\title{
Spectrum and antibiotic sensitivity of bacteria contaminating the upper gut in patients with malabsorption syndrome from the tropics
}

\author{
Ujjala Ghoshal', Uday C Ghoshal², Piyush Ranjan², Subhash R Naik² and \\ Archana Ayyagari ${ }^{1}$
}

Address: ${ }^{1}$ Department of Microbiology Sanjay Gandhi Postgraduate Institute of Medical Sciences Lucknow 226014, India and ${ }^{2}$ Department of Gastroenterology Sanjay Gandhi Postgraduate Institute of Medical Sciences Lucknow 226014, India

Email: Ujjala Ghoshal - ujjala@sgpgi.ac.in; Uday C Ghoshal* - ghoshal@sgpgi.ac.in; Piyush Ranjan - pranjan@sgpgi.ac.in;

Subhash R Naik - ghoshal@sgpgi.ac.in; Archana Ayyagari - archana@sgpgi.ac.in

* Corresponding author

Published: 24 May 2003

BMC Gastroenterology 2003, 3:9

This article is available from: http://www.biomedcentral.com/I47I-230X/3/9

(c) 2003 Ghoshal et al; licensee BioMed Central Ltd. This is an Open Access article: verbatim copying and redistribution of this article are permitted in all media for any purpose, provided this notice is preserved along with the article's original URL.
Received: 15 January 2003

Accepted: 24 May 2003

\begin{abstract}
Background: Various causes of malabsorption syndrome (MAS) are associated with intestinal stasis that may cause small intestinal bacterial overgrowth (SIBO). Frequency, nature and antibiotic sensitivity of SIBO in patients with MAS are not well understood.

Methods: Jejunal aspirates of 50 consecutive patients with MAS were cultured for bacteria and colony counts and antibiotic sensitivity were performed. Twelve patients with irritable bowel syndrome were studied as controls.

Results: Culture revealed growth of bacteria in 34/50 (68\%) patients with MAS and $3 / 12$ controls $(p<0.05)$. Colony counts ranged from $3 \times 10^{2}$ to $10^{15}$ (median $\left.10^{5}\right)$ in MAS and 100 to 1000 (median 700) CFU/ml in controls ( $\mathrm{p}$ 0.003). $21 / 50$ (42\%) patients had counts $\geq 10^{5} \mathrm{CFU} / \mathrm{ml}$ in MAS and none of controls $(p<0.05)$. Aerobes were isolated in $34 / 34$ and anaerobe in $1 / 34$. Commonest Gram positive and negative bacteria were Streptococcus species and Escherichia coli respectively. The isolated bacteria were more often sensitive to quinolones than to tetracycline (ciprofloxacin: $39 / 47$ and norfloxacin: $34 / 47$ vs. tetracycline 19/47, <0.01), ampicillin, erythromycin and cotrimoxazole (21/44, 14/22 and 24/47 respectively vs. tetracycline, $p=n s)$.
\end{abstract}

Conclusions: SIBO is common in patients with MAS due to various causes and quinolones may be the preferred treatment. This needs to be proved further by a randomized controlled trial.

\section{Background}

Small intestinal bacterial overgrowth syndrome (SIBO) is defined as overgrowth of $\geq 10^{5}$ colony forming unit (CFU) per $\mathrm{ml}$ of bacteria in the proximal small bowel [1]. Some authors considered a diagnosis of SIBO even with a lower colony count $\left(\geq 10^{3} \mathrm{CFU} / \mathrm{ml}\right)$ if the species of bacteria isolated in jejunal aspirate were those which, colonize large bowel $[2,3]$. Various anatomical lesions of small bowel and slowing of its motility may lead to bacterial overgrowth [4]. Several specific diseases e.g. celiac disease, 
tropical sprue (TS) and parasitic infestations have been shown to reduce intestinal motility [5-7]. Classic radiological findings of 'segmentation', 'flocculation' and dilatation of small bowel in barium series in patients with malabsorption are secondary to intestinal stasis [8]. Therefore, patients with specific causes of MAS like TS, celiac disease, parasitic infestations are also prone to SIBO. Frequency, nature and clinical significance of SIBO in patients without any other known cause of malabsorption syndrome (MAS, e.g. TS, celiac disease) are well established. Despite description of small bowel stasis in patients with various known causes of MAS, reports on frequency, nature and antibiotic sensitivity of SIBO in these patients are scant. We hypothesize that patients with MAS, irrespective of etiology, might have SIBO.

Studies on bacterial population contaminating upper gut and their antibiotic sensitivity pattern from developed countries are sparse $[9,10]$. Sensitivity of these bacteria to currently available antibiotics has been reported only once [9]. There is no study on spectrum of bacteria and their sensitivity pattern to various antibiotics in patients with MAS from developing countries. SIBO is often treated with repeated courses of antibiotics. Tetracycline was the mainstay of therapy for SIBO in past [11]. With the availability of several newer safe, effective and nonabsorbable antibiotics, studying in vitro sensitivity of bacteria isolated from small bowel of these patients to such antibiotics appears worthwhile. Accordingly, we undertook this study prospectively.

\section{Methods \\ Patients}

50 patients (age $44 \pm 8.5$ years, 31 males) with chronic diarrhea, weight loss and anemia diagnosed as having MAS attending Luminal Gastroenterology Clinic of our department were studied. Diagnosis of MAS was established by abnormal D-xylose test $(<1 \mathrm{~g} / 5 \mathrm{~g} / 5 \mathrm{~h})$ with or without abnormal 24-h fecal fat estimation $(\geq 7 \mathrm{~g} / \mathrm{d})$ while on fat loading by Van de Kamer's technique [12]. The clinical details of these patients have been reported elsewhere $[6,13,14]$. No patient received antibiotics within 8 weeks preceding the study. The criteria used for diagnosis of various causes of MAS were as follows: Celiac disease, a) presence of anti-endomysial antibody, b) suggestive histology and c) response to gluten free diet; giardiasis, demonstration of trophozoite form of the organism in stool and/or duodenal biopsy; intestinal tuberculosis, a) demonstration of acid fast bacilli in intestine or extra-intestinal site and b) response to therapy; strongyloidiasis, demonstration of the parasite in intestinal biopsy and/or stool microscopy; intestinal lymphangiectasia, dilated lymphatic channels in subepithelial location in intestinal biopsy; acquired immunodeficiency syndrome by serology; hypogamma- globulinemia by serum immunoglobulin estimation; TS, a) no specific cause for MAS and, b) persistent response to tetracycline and folic acid.

The diagnoses of patients included in this study were as follows, tropical sprue (16), celiac disease (5), intestinal tuberculosis (3), panhypogammaglobulinemia (2) one of whom had strogyloidiasis, selective IgA deficiency (1), acquired immunodeficiency syndrome (1), giardiasis (2) and intestinal lymphangiectasia (1). Seven patients had SIBO secondary to either structural lesions or motility abnormality of gut (ileocolic anastomosis in 4, diverticulosis in 1, intestinal hypomotility due to scleroderma in 1 and diabetic autonomic neuropathy and hypothyroidism in 1). In 12/50 patients cause of MAS could not be ascertained. The protocol of the study was approved by the ethics committee of the institute and patients gave consent for inclusion into the study.

\section{Controls}

12 patients with constipation predominant irritable bowel syndrome (IBS) diagnosed by Rome criteria [15] were used as controls. Clinical details of these patients have been reported elsewhere [6]. No patient with IBS had biochemical evidence of MAS [normal D-xylose test $(\geq 1$ / $\mathrm{g} / 5 \mathrm{~g} / 5 \mathrm{~h}$ ) and fecal fat estimation by Sudan III stain of spot stool specimen (<10 droplets/high power field)]. Endoscopic jejunal biopsy was normal in them. None of them had received antibiotics, pro or anti-motility and anti-secretory drugs within 8 weeks preceding the study.

\section{Jejunal aspiration}

Jejunal aspirate was collected during jejunoscopy with a pediatric colonoscope and a catheter described earlier [13]. Briefly, the catheter assembly had an inner tube that was $3 \mathrm{~cm}$ longer than the outer tube. A rubber obturator blocked the mouth of the outer tube (Fig. 1). The assembly was sterilized by autoclaving. On reaching the jejunum (confirmed by fluoroscopic examination in initial few patients and by length of endoscope inserted), the catheter assembly was introduced through the biopsy channel of a sterilized pediatric colonoscope. The inner tube was then pushed beyond the tip of the outer tube once the outer tube was $4-5 \mathrm{~cm}$ ahead of the tip of the endoscope. This led to dislodgement of the rubber obturator from the tip of the outer tube. Jejunal aspirate was collected through the inner tube with a sterile syringe, which was used for aerobic and anaerobic bacterial culture (transported in Robertson's cooked meat medium for the latter), colony count and drug sensitivity pattern.

\section{Bacteriological studies}

Smears were prepared from jejunal aspirates, fixed, Gram stained and examined for presence of Gram positive and negative organisms. Bacterial species were cultured and 


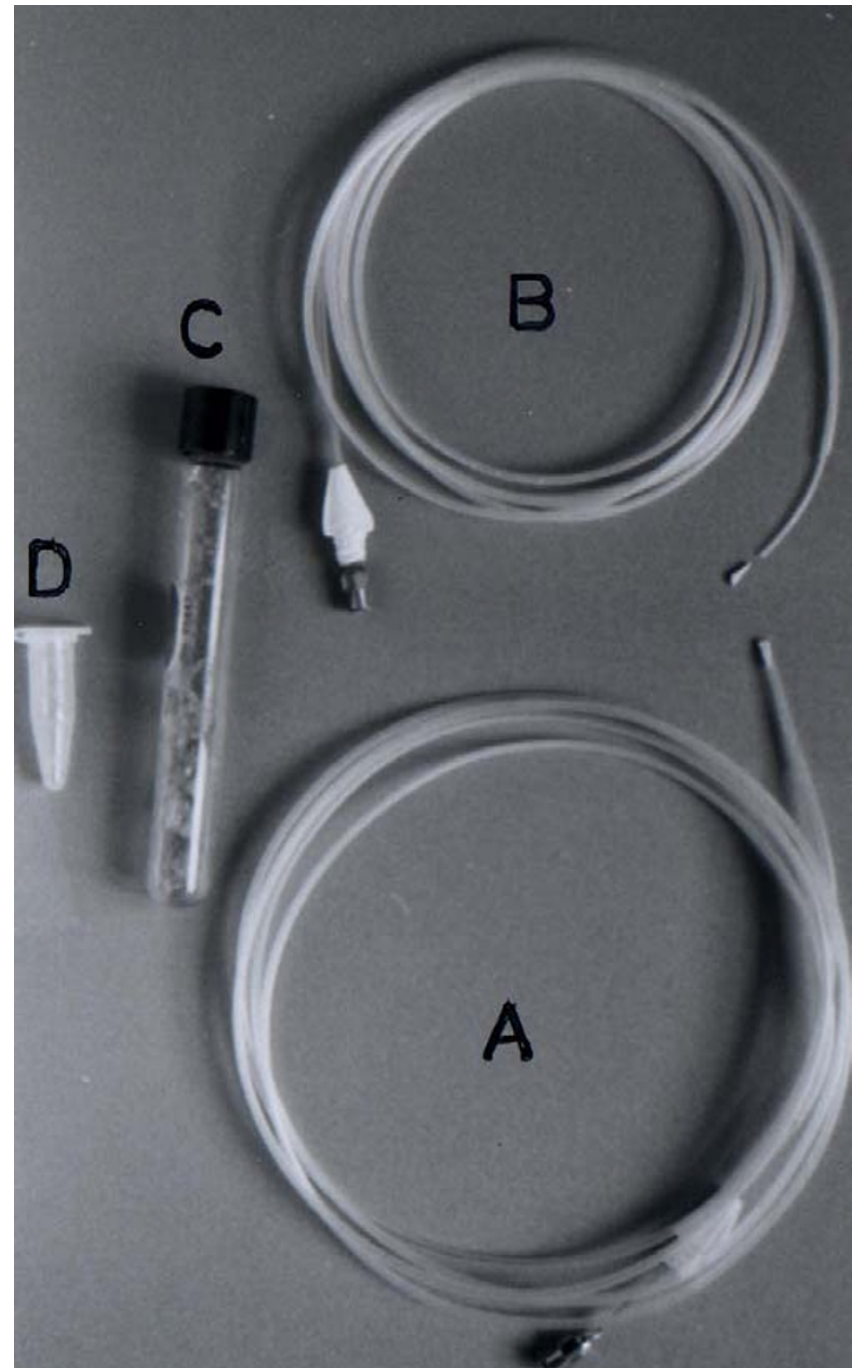

\section{Figure I}

Assembly used for jejunal aspiration. (a) jejunal aspiration catheter with inner tube housed inside the outer tube. The tip of the outer tube is closed with a rubber obturator. (b) Note that the rubber obturator has been dislodged after inner tube has been pushed to come out from the tip of the outer tube. (c) Robertson's cooked meat media used to transport jejunal aspirate for anaerobic culture. (d) Sterile tube used to transport jejunal aspirate for aerobic culture.

isolated using standard techniques [16]. Briefly, for aerobic culture, samples were homogenized by vortexing and then diluted serially with sterile distilled water. Dilutions from $5 \times 10^{-1}$ to $5 \times 10^{-4}$ were prepared. Aliquots of nondiluted sample and each dilution (100 $\mu \mathrm{l}$ each) were plated on blood agar and MacConkey agar. After 24 to 48$\mathrm{h}$ incubation at $37^{\circ} \mathrm{C}$, colonies were counted and bacterial species identified using standard techniques $[16,17]$.
Dilutions were made in Robertson's cooked meat broth for anaerobic culture. Undiluted sample and each dilution $(100 \mu \mathrm{l}$ each) were subcultured on Wilkins-Chalgren agar. For anaerobic culture anaerobic jars (McIntosh) were used. For gassing the culture evacuation replacement system (Anoxomate, Mart-Netherland) was used. The standard anaerobic recipe has 3 evacuation replacement cycles. In the first evacuation phase of the standard anaerobic culture $80 \%$ of the jar volume was evacuated. The anoxomate achieves this with high accuracy due to high precision pressure sensor. In the successive replacement, the jar was filled with oxygen free gas mixture (Nitrogen). The jar was finally filled with a gas mixture containing 80\%-90\% nitrogen, 5\%-10\% hydrogen and carbon dioxide. Strains of Clostridium difficile, Clostridium perfringens, Bacteroides fragilis and gram negative cocci were used as positive control with each batch. Pseudomonas aeruginosa was used as negative control. Cultures were examined for bacterial growth after incubation for 48 -h and if negative, after 5 days at $37^{\circ} \mathrm{C}$ in an anaerobic chamber. In case of bacterial growth, colonies were counted and bacterial species identified using standard techniques. Rogosa agar was used [16] for lactobacilli and was incubated in anaerobic conditions. Bacterial counts were expressed as logarithm of colony forming units per ml of jejunal fluid. Total bacterial colonies and count of each species were obtained.

\section{Antibiotic sensitivity}

All bacterial strains were subjected to in vitro antibiotic sensitivity test. Antibiotic discs (Himedia, Mumbai, India), namely ampicillin $(10 \mu \mathrm{g})$, ampicillin and salbactum $(10 \mu \mathrm{g}$ each), tetracycline $(30 \mu \mathrm{g})$, co-trimoxazole (trimethoprim / sulfamethoxazole $1.25 / 23.75 \mu \mathrm{g}$ ), erythromycin $(15 \mu \mathrm{g})$, norfloxacin $(10 \mu \mathrm{g})$, ciprofloxacin $(5 \mu \mathrm{g})$ and cephalexin $(30 \mu \mathrm{g})$ were used. We chose these antibiotics as these are orally administered and therefore, are likely to be preferred by the clinicians in the treatment of SIBO. The antibiotic discs were stored at $4^{\circ} \mathrm{C}$ before use. Antibiotic sensitivity test was performed by modified Stoke's method [17]. Briefly, Muller Hinton's agar was prepared and its $\mathrm{pH}$ was adjusted to 7.3. It was poured to a depth of $4 \mathrm{~mm}$ on flat-bottomed $9-\mathrm{cm}$ petri dishes. These were dried before use. The area of petri dish was arbitrarily divided into three parts, central area for control organisms and two areas on either side of it, for test organisms. The control organisms consisted of Escherichia coli [National Collection of Type Culture (NCTC) 10418], Staphylococcus aureus (NCTC 6571) and Pseudomonas aeruginosa (NCTC 10662) for coliforms, Staphylococcus and pseudomonads respectively. An inoculum of the test organism was prepared by emulsifying part of the growth from each of 5 similar colonies in saline. Turbidity of the suspension was adjusted to $0.5 \mathrm{McF}$ arland standard spectrophotometrically at $530 \mathrm{~nm}$ wavelength. Overnight incubation of this inoculum produced semi-confluent 
growth. Sterile cotton swabs were impregnated with the test and control organisms separately. These swabs were used to inoculate the specified areas of the petri dishes with test and control organisms. A gap of 2-3 mm was left between test and control strains. Antibiotic discs were applied with light pressure on the agar surface using flamed forceps after the inoculum had dried. The petri dishes were incubated at $37^{\circ} \mathrm{C}$ for 16 to 18 -h.

The radial width of the zones outside the antibiotic discs was measured in $\mathrm{mm}$. The zones of inhibition of the test organisms were compared with those of control strains. The results were interpreted based on measurement of zone of inhibition $(\mathrm{mm})$ in test organisms as compared with the controls as follows: (a) sensitive: equal to, greater than or not less than $3-\mathrm{mm}$ as compared with controls, (b) intermediate: $\geq 2$-mm but smaller than controls by $>3$ $\mathrm{mm}$, (c) resistant: $\leq 2-\mathrm{mm}$.

\section{Statistical analysis}

Nominal variables were analyzed by Chi-square test with Yates' correction as applicable. Numerical variables were analyzed by Mann-Whitney $U$ test as the data were not expected to have normal distribution. A p value of $<0.05$ was considered as significant.

\section{Results}

\section{Gram staining}

Gram positive cocci were found in 8/50, Gram negative bacilli in 13/50 and both Gram positive cocci and negative bacilli in 7/50 patients with MAS. In other 22 patients Gram staining did not show any bacteria.

Frequency, nature of the bacteria and colony count Culture revealed growth of bacteria in $34 / 50(68 \%)$ patients with MAS and 3/12 patients with IBS ( $\mathrm{p}<0.05)$.
Total colony count ranged from $3 \times 10^{2}$ to $1 \times 10^{15}$ colony forming unit (CFU)/ml (median $10^{5}$ ) in MAS and 1001000 (median 700) CFU/ml in patients with IBS ( $\mathrm{p}$ $0.003) ; 21 / 50(42 \%)$ patients had with MAS and none of 12 with IBS had colony count $\geq 10^{5} \mathrm{CFU} / \mathrm{ml}(\mathrm{p}<0.05)$. In patients with MAS, aerobes were isolated in 34/34 and anaerobe in $1 / 34$ with positive culture. Two bacterial species were grown in jejunal aspirate of 13 patients and three bacterial species in one patient. In the remaining 20 patients, growth of a single bacterial species was obtained. Frequency of isolation of different bacteria and colony count of each species of bacteria in patients with MAS are shown in table $1 . \geq 10^{5} \mathrm{CFU} / \mathrm{mL}$ bacteria grew in $6 / 16$ patients with TS, 2/5 with celiac disease, $1 / 3$ with intestinal tuberculosis, $1 / 1$ with panhypogammaglobulinemia and Strongyloidiasis, 1/1 with selective IgA deficiency, all seven with SIBO secondary to structural and motility abnormality and 3/12 with MAS without a known cause.

\section{Sensitivity testing}

In vitro sensitivity to commonly used orally absorbed antibiotics showed (table 2) that bacteria isolated from small bowel were more often sensitive to quinolones (ciprofloxacin and norfloxacin) than to tetracycline (39/47 and $34 / 47$ vs $19 / 47, \mathrm{p}<0.0001$ and $<0.01$, respectively); it is important to note that tetracycline is commonly used to treat chronic diarrhoea and malabsorption associated with bacterial contamination of small bowel $[10,11]$. There was no difference in sensitivity to ampicillin, erythromycin, co-trimoxazole with that of tetracycline $(21 / 44$, $14 / 22$ and $24 / 47$ vs. $19 / 47, \mathrm{p}=\mathrm{ns}$ ). $30 / 44$ and $25 / 40$ bacterial species were sensitive to ampicillin and sulbactam combination and cephalexin respectively.

Table I: Frequency of isolation and colony counts of different bacteria in patients with malabsorption syndrome.

\begin{tabular}{llll}
\hline Name of bacteria & Frequency of isolation* & Median colony count (CFU/ml) & Range (CFU/ml) \\
\hline Aerobes & & & $10^{3}$ to $>10^{5}$ \\
Escherichia coli & 12 & $10^{5}$ & $1.6 \times 10^{3}$ to $>10^{5}$ \\
Streptococcus species (Non-A, non-B, non-D) & 12 & $>10^{5}$ & $6 \times 10^{2}$ to $>10^{5}$ \\
Klebsiella pneumoniae & 5 & $8 \times 10^{4}$ & $1.6 \times 10^{3}$ to $>10^{5}$ \\
Enterococcus fecalis & 3 & $10^{5}$ & - \\
Enterococcus fecium & 1 & $>10^{5}$ & $3 \times 10^{2}$ to $>10^{5}$ \\
Staphylococcus aureus & 5 & $>10^{5}$ & $3.6 \times 10^{3}$ to $10^{5}$ \\
Pseudomonas aeruginosa & 3 & $6 \times 10^{5}$ & $4 \times 10^{2}$ to $>10^{5}$ \\
Acinetobacter baumanii & 3 & $10^{4}$ & - \\
Citrobacter freundii & 1 & $10^{3}$ & - \\
Proteus mirabilis & 1 & $>10^{5}$ & - \\
Anaerobes & 1 &
\end{tabular}

*Jejunal aspirate of 20 patients grew one, 13 two and one three bacterial species. 
Table 2: Sensitivity of the bacteria isolated from jejunal aspirate to various antibiotics.

\begin{tabular}{|c|c|c|c|c|c|c|c|c|}
\hline \multirow[t]{2}{*}{ Bacteria } & \multicolumn{8}{|l|}{ Sensitive to } \\
\hline & Ampicillin & Ampicillin Sulbactam & Tetracyclin & Cotrimox & Erythro & Norflox & Ciproflox & Cephalexin \\
\hline E. coli $(n=12)$ & 3 & 5 & 4 & 5 & NT & 7 & 9 & 5 \\
\hline Streptococcus sp. $(\mathrm{n}=12)$ & 9 & 11 & 6 & 5 & 9 & 11 & 12 & 9 \\
\hline E. fecalis $(n=3)$ & 3 & 3 & 1 & 0 & 1 & 1 & 1 & NT \\
\hline E. fecium $(\mathrm{n}=1)$ & I & I & 0 & 0 & I & 0 & 0 & NT \\
\hline S. aureus $(n=5)$ & 3 & 4 & 2 & 5 & 3 & 4 & 5 & 3 \\
\hline C. freundi $(\mathrm{n}=1)$ & 0 & 1 & 0 & 1 & NT & 1 & I & 1 \\
\hline K. pneumoniae $(n=5)$ & 1 & 3 & 2 & 3 & NT & 3 & 4 & 3 \\
\hline P. mirabilis $(\mathrm{n}=1)$ & 1 & 1 & 0 & 0 & NT & 1 & I & I \\
\hline A. baumanii $(n=3)$ & 0 & 0 & 2 & 2 & NT & 3 & 3 & 3 \\
\hline P. aeruginosa $(\mathrm{n}=3)$ & NT & NT & 1 & 2 & NT & 3 & 3 & NT \\
\hline B. melaninogenicus $(n=1)$ & 0 & 1 & 1 & I & 0 & 0 & 0 & 0 \\
\hline Total $(n=47)$ & $21 / 44(48)$ & $30 / 44 *(68)$ & $19 / 47 *(40)$ & $24 / 47(5 I)$ & $14 / 22(64)$ & $34 / 47^{*}(72)$ & $39 / 47 \$$ & $25 / 40(62.5)$ \\
\hline
\end{tabular}

Figures within parenthesis indicate percentages. NT: not tested. ${ }^{*} \mathrm{p}<0.01$; ${ }^{\$} \mathrm{p}<0.000 \mathrm{I}$ (Chi-squared test)

\section{Discussion}

In this study we found that the spectrum of bacteria isolated from upper small bowel in patients with malabsorption syndrome from the tropics are somewhat similar to that reported from the west [9]; these bacteria are often resistant to tetracycline, co-trimoxazole, ampicillin and sensitive to quinolones. Therefore, our data suggest the need for undertaking randomized controlled trial of these orally administered antibiotics in the treatment of SIBO and contaminated small bowel syndrome in the tropics.

We have shown that SIBO was common in MAS due to any cause (e.g. TS, celiac disease, parasitic infestation, immunodeficiency states) and resulted from both Gram positive and Gram negative bacteria. SIBO was diagnosed using standard definition $\left(\geq 10^{5} \mathrm{CFU} / \mathrm{ml}\right.$ bacteria in jejunal aspirate) [1]. Predominant Gram positive organism was streptococcus species and the predominant Gram negative organism was Escherichia coli. This is accordance with the earlier report from the west [9]. Anaerobes were infrequently found in our study. This might be related to the fastidious nature of anaerobes and failure to grow even on exposure to small quantity of oxygen [18]. Other reasons could be related to differences in patient population included in our study. We studied patients with MAS due to other primary causes; in contrast, earlier studies included patients with SIBO syndrome [9]. Lower colony counts of aerobes could be the other reason for lower frequency of anaerobes as aerobes utilize oxygen and help in growth of anaerobes [19]. Several isolated studies documented SIBO either using microbiological techniques or glucose hydrogen breath test in patients with celiac disease [20], TS [6], parasitic infestation of small bowel $[7,13]$ and hypogammaglobulinemia [21]. In this study we documented frequent occurrence of SIBO in patients with various causes of MAS as a group. Such secondary SIBO in patients with another cause of MAS may have clinical significance as it can further compound malabsorption of nutrients in addition to the primary disease contributing to it. Studies from Burma suggested SIBO as a cause of malnutrition in pediatric population $[22,23]$. Secondly, at times a transient response to antibiotics resulting from eradication of such secondary SIBO may mislead the clinician trying to establish the diagnosis of etiology of MAS.

We found frequent resistance to the drugs that are often used in the treatment of SIBO syndrome. Over half of bacteria were resistant to tetracycline, the drug that has been considered as the first line antibiotic in the treatment of SIBO when not guided by antibiogram [11], a quite common practice. Most strains were also resistant to the combination of trimethoprim-sulfamethoxazole. This is in contrast to the earlier western report showing infrequent resistance to most antibiotics [9]. These discrepancies might be explained by differing practice of antibiotic use in different countries. Frequent resistance to commonly used antibiotics in India might owe to over the counter availability and frequent unnecessary use of these antibiotics. In the present study, we deliberately chose to report sensitivity patterns of orally used antibiotics as parenteral antibiotics are rarely used in treatment of SIBO. Most of bacteria isolated were sensitive to both ciprofloxacin and norfloxacin. However, we believe that norfloxacin may be preferred over ciprofloxacin, since norfloxacin has low systemic absorption [24] and therefore, may have infrequent side effects and may be safe particularly during pregnancy. Patients with SIBO often need long-term and repeated courses of antibiotics [25] and therefore, those with lesser toxicity and lower systemic absorption would 
be preferred. However, this needs to be proved by randomized controlled trial. A recent randomized cross over study on ten patients with SIBO from developed countries documented efficacy of norfloxacin in reducing diarrhoea and breath hydrogen [26].

In conclusion, SIBO is common in patients with malabsorption syndrome due various causes in the tropics and norfloxacin may be considered in its treatment. Our in vitro data also serve as a starting point for further randomized controlled trial of norfloxacin in treatment of SIBO.

\section{Competing interest \\ None declared.}

\section{Authors' contributions}

Ujjala Ghoshal conceived the study, performed all microbiological works and analyzed and drafted the manuscript. Uday C Ghoshal designed the study, participated in clinical and endoscopic works and helped the first author in analyzing the data and in drafting the manuscript. Piyush Ranjan participated in clinical works. SR Naik supervised planning, execution and drafting the manuscript. Archana Ayyagari supervised the microbiological works. All authors read and approved the manuscript.

\section{Acknowledgement}

The authors thank the endoscopy staff of the Department of Gastroenterology and laboratory staff of the Department of Microbiology at their institution for technical help.

\section{References}

I. Toskes PP: Bacterial overgrowth of the gastrointestinal tract Adv Int Med 1993, 38:387-407.

2. Simon GL and Gorbach SL: The human intestinal microflora Dig Dis Sci 1986, 3 I: |47-62.

3. Justensen T, Haagen Nielsen $\mathrm{O}$ and Jacobson $\mathrm{E}$ : The normal cultivable microflora in upper jejunal fluid in healthy adults Scand J Gastroneterol 1984, 19:279-82.

4. Ballen LS and Russel RM: Bacterial overgrowth syndrome Clinical Perspectives in Gastroenterology 2000:225-31.

5. Chiarioni G, Bassotti $G$ and Germani U: Gluten-free diet normalizes mouth-to-cecum transit of a caloric meal in adult patients with celiac disease Dig Dis Sci 1997, 42:2100-5.

6. Ghoshal UC, Ghoshal U, Ayyagari A, Ranjan P, Krishnani N, Misra A, Aggarwal $R$, Naik $S$ and Naik SR: Tropical sprue is associated with contamination of small bowel with aerobic bacteria and reversible prolongation of orocaecal transit time J Gastroenterol Hepatol 2003, I 8:540-7.

7. Dwinell MB, Bass P, Schaefer DM and Oaks JA: Tapeworm infection decreases intestinal transit and enteric aerobic bacterial population Am J Physiol 1997, 273:G480-5.

8. Eisenberg RL: Gastrointestinal radiology: A pattern approach Philadelphia: JB Lippincott Company 1990:44 I-5I.

9. Bouhnik Y, Alain S, Attar A, Flourie B, Raskine L, Sanson-Le Pors MJ and Rambaud JC: Bacterial populations contaminating upper gut in patients with small intestinal bacterial overgrowth syndrome Am J Gastroenterol 1999, 94:1327-31.

10. Isaacs PET and Kim YS: The contaminated small bowel syndrome $A m$ J Med 1979, 67:1049-56.

II. Tabacquali S: The pathophysiological role of small intestinal bacterial flora Scand J Gastroenterol 1970, 5:139-63.
12. Raffensperger EC, D'Agostino F, Manfredo H, Ramirez M, Brooks FP and O'Neill F: Fecal fat excretion: an analysis of four years' experience Arch Intern Med 1967, I I 9:573-6.

13. Ghoshal UC, Ghoshal U, Kumar A, Jain A, Aggarwal R, Misra A, Ayyagari $A$ and Naik SR: Strongyloides stercoralis infestation associated with septicemia due to intestinal transmural migration of bacteria J Gastroenterol Heptol 2002, I 7:|33|-3.

14. Ranjan P, Ghoshal UC, Ghoshal U, Aggarwal R, Ayyagari A, Naik S and Naik SR: A prospective study of etiological spectrum of malabsorption syndrome in North India Indian J Gastroenterol 200 I, 20(Suppl 2):Al9.

15. Drossman DA, Camilleri M, Mayer EA and Whitehead WE: AGA technical review on irritable bowel syndrome Gastroenterology 2002, I 23:2 |08-31.

16. Collee JG, Miles RS and Walt B: Tests for the identification of bacteria In: Mackie and McCartney Practical Medical Microbiology Edited by: Collee JG, Fraser AG, Marmion BP, Simmons A. New York: Churchill Livingstone; 1996: I 3 |-49.

17. Anonymous: Processing clinical specimens for anaerobic bacteria: Isolation and identification procedures In: Bailey and Scott's Diagnostic Microbiology Edited by: Baron EJ, Peterson LR, Finegold SM. Philadelphia: Mosby; 1994:474-503.

18. Ananthanarayan $\mathrm{R}$ and Panikar CKJ: Textbook of microbiology Chennai: Orient Longman 1999:244-9.

19. Levitt MD: Oxygen tension in the gut $N$ Engl J Med 1970, 282: $1039-40$.

20. Abdulkarim AS, Burgart LJ, See J and Murray JA: Etiology of nonresponsive celiac disease: Results of a systemic approach $\mathrm{Am} J$ Gastroenterol 2002, 97:2016-21.

21. Nussinson E, Lahav M, Berebi A, Estrov Z, Zur S and Resnitzky P: Secretory piece and IgA deficiency in a patient with Waldenstrom's macroglobulinemia Am J Gastroenterol I 986, 81 : 995-8.

22. Pereira SP, Khin-Maung U, Bolin TD, Duncombe VM, Nyunt-NyuntWai, Myo-Khin and Linklater JM: A pattern of breath hydrogen excretion suggesting small bowel bacterial overgrowth in Burmese village children J Pediatr Gastroenterol Nutr I991, I 3:3238.

23. Khin-Maung U, Bolin TD, Pereira SP, Duncombe VM, Myo-Khin , Nyunt-Nyunt-Wai and Linklater JM: Epidemiology of small bowel bacterial overgrowth and rice malabsorption in Burmese (Myanmar) village children Am J Trop Med Hyg 1992, 47:298-304.

24. Archar GL and Polk KE: Approach to therapy for bacterial diseases In: Harrison's Principles of Internal Medicine Edited by: Braunwald E, Fauci AS, Kasper DL, Hauser SL, Longo DL, Jameson LR. McGraw-Hill, Inc; 200I:867-82.

25. King CE and Toskes PP: Small intestinal bacterial overgrowth Gastroenterology 1979, 76:1035-55.

26. Attar A, Flourie B, Rambaud JC, Franchisseur C, Ruszniewski P and Bouhnik $Y$ : Antibiotic efficacy in small intestinal bacterial overgrowth-related diarrhoea: a crossover, randomized trial Gastroenterology 1999, I I 7:794-7.

\section{Pre-publication history}

The pre-publication history for this paper can be accessed here:

http://www.biomedcentral.com/1471-230X/3/9/prepub 